\title{
Serum Level of Vitamin D3 and Renal Stone in Children
}

\author{
Shahin Abbaszadeh, ${ }^{1}$ Ehsan Shahverdi, ${ }^{2,}{ }^{*}$ Fatemeh Beiraghdar, ${ }^{3}$ Fatemeh Heydari, ${ }^{1}$ Mohammad Ali \\ Najafizadeh, ${ }^{2}$ Mohammad Amin Konjedi, ${ }^{2}$ Fatemeh Shafizadeh Barmi, ${ }^{4}$ and Yasaman Vakiloroaya ${ }^{5}$ \\ ${ }^{1}$ Department of Urology, Baqiyatallah University of Medical Sciences, Tehran, IR Iran \\ ${ }^{2}$ Students' Research Committee, Baqiyatallah University of Medical Sciences, Tehran, IR Iran \\ ${ }^{3}$ Department of Pediatrics, Baqiyatallah University of Medical Sciences, Tehran, IR Iran \\ ${ }^{4}$ Department of Microbiology, Tehran Medical Branch, Islamic Azad University, Tehran, IR Iran \\ ${ }^{5}$ Young Researchers Club, Tehran Medical Branch, Islamic Azad University, Tehran, IR Iran \\ "Corresponding author: Ehsan Shahverdi, Baqiyatallah University of Medical Sciences, Mollasadra st., Vanaq sq., Tehran, IR Iran. Tel: +98-2188620826, E-mail: \\ shahverdi_ehsan@yahoo.com
}

Received 2015 November 03; Revised 2016 March 24; Accepted 2016 May 22.

\begin{abstract}
Background: Due to high prevalence of vitamin D insufficiency in Iranian children, researchers found a low level of vitamin D among patients with nephrolithiasis.

Objectives: Since previous studies showed hyper-vitaminosis D in patients with renal stone, the current study aimed to clarify this paradox.

Materials and Methods: In this cross-sectional study, 100 pediatric patients with renal stone referred to Pediatric Urology and Nephrology Clinic of Baqiyatallah Hospital in Tehran, Iran, in 2014 were selected using a simple sampling method. The serum level of vitamin D3 was measured in a laboratory and the correlation between vitamin D3 and other variables were evaluated.

Results: One-hundred pediatric patients, $64 \%$ male and 36\% female, with renal stone were evaluated. The serum level of vitamin D and calcium had no significant difference between male and female patients. Four patients had vitamin D deficiency, 31 patients had vitamin D insufficiency and others had sufficient levels of vitamin D. There was a direct significant correlation between the level of vitamin D and calcium serum level. Family history of renal colic did not affect the serum levels of vitamin D and calcium. The serum level of vitamin D was significantly higher in patients with bilateral renal stone compared to patients with unilateral renal stone. Conclusions: Serum levels of vitamin D in children with urinary stones were low. The level of vitamin D deficiency was significantly correlated with disease severity and serum level of calcium.
\end{abstract}

Keywords: Renal Stone, Vitamin D, Calcium, Pediatric

\section{Background}

Urinary stones are common problems among patients admitted to emergency and urology departments (1). Incidence of urinary stones in different locations is reported at $1 \%-5 \%$; it is estimated to be $2 \%-3 \%$ in developed countries and $0.5 \%-1 \%$ in the developing countries (2). In children, it is usually different. Urinary stones in children are more common in males and 70\% of cases are located in the upper urinary tract $(3,4)$. Studies indicated that about $90 \%$ of calcium urinary stones are associated with a metabolic disorder. Vitamin D is one of the important metabolic factors in patients with urinary stones (5-8).

Many studies showed the relationship between urinary stones and hypervitaminosis D (9). But in most studies in Iran, more people with kidney stones were with hypovitaminosis $\mathrm{D}(10)$.

\section{Objectives}

The current study aimed to determine the role of vitamin D in urinary stone formation in children.

\section{Materials and Methods}

The current cross-sectional study was conducted after receiving the ethics approval and patient informed consent from 20 March to 20 November 2014. One-hundred 1-16 year-old children with renal stone, were selected using a simple sampling method in Baqiyatallah hospital of Tehran, Iran. Renal stone was diagnosed based on ultrasound technique by a pediatric nephrologist and a pediatric urologist.

The parents were asked to fill out a questionnaire including demographic data: age, gender and family history

Copyright (c) 2016, Iranian Society of Pediatrics. This is an open-access article distributed under the terms of the Creative Commons Attribution-NonCommercial 4.0 International License (http://creativecommons.org/licenses/by-nc/4.0/) which permits copy and redistribute the material just in noncommercial usages, provided the original work is properly cited. 
of renal stone, ultrasound findings including uni- or bilateral stone and laboratory data including calcium and vitamin D serum levels. The level of vitamin D (cholecalciferol for serum levels of $25(\mathrm{OH})=25 \mathrm{OH} \mathrm{D})$ in one unit $\mathrm{ng} / \mathrm{mL}$ was measured using Aylksys chemiluminescent methods with Dia Sorin kit and then interpreted based on the following table: 30 - $100 \mathrm{ng} / \mathrm{mL}=$ normal, $10-30 \mathrm{ng} / \mathrm{mL}=$ insufficient and $<10 \mathrm{ng} / \mathrm{mL}=$ deficient.

One to sixteen year-old children with renal stones were enrolled in the study. Cases with any vitamin D disturbances were excluded.

\subsection{Statistical Analysis:}

Data were analyzed using statistical package for social sciences (SPSS) version 18 (SPSS Inc. Chicago, IL) for windows. Normal distribution variables (approved by onesample Kolmogorov-Smirnov test) were compared using independent sample T-test between the groups and paired sample T-test within the groups. Chi-square test was also used to compare categorical variables in the two groups. A $P$ value of $<0.05$ was considered statistically significant.

\section{Results}

A total of 100 children (64 males and 36 females) with urinary stones and the mean age of $4.46 \pm 2.11$ years were evaluated. Table 1 shows demographic data. According to the table, the mean age of patients in both groups showed no significant difference between males and females ( $\mathrm{P}=$ $0.13)$.

A total of 20 children (20\%) had a positive family history of renal stones. There was no significant difference between male and female patients in terms of positive family history of renal stones $(\mathrm{P}=0.52)$ (Table 1$)$.

According to Table 1, 29 children (29\%) and 71 children (71\%) had bilateral and unilateral renal stones, respectively. There was no significant difference in distribution of uniand bilateral stone between males and females $(\mathrm{P}=0.08)$.

Serum level of vitamin D3 in total was $37.45 \pm 10.86$ $\mathrm{ng} / \mathrm{mL}$. The mean serum levels of vitamin D3 showed no significant difference between male and female subjects ( $\mathrm{P}=$ $0.74)$. Four children (4\%) had vitamin D deficiency, 31 children (31\%) had insufficient vitamin D levels and 65 children (65\%) had sufficient vitamin D levels. There was no significant difference between males and females regarding vitamin $\mathrm{D}$ deficiency $(\mathrm{P}=0.66)$ (Table 1 ).

The mean total serum calcium level was $0.97 \pm 10.6$ $\mathrm{mg} / \mathrm{dL}$. According to Table 1 , serum calcium levels showed no significant difference between male and female subjects $(P=0.16)$.

Pearson correlation test showed significant correlation between serum levels of calcium and vitamin $\mathrm{D} 3(\mathrm{P}<$
0.001 and $r=0.41$ ) (Figure 1 ). The serum levels of calcium in patients with a deficiency of vitamin D3 was $9.20 \pm 0.21$ $\mathrm{mg} / \mathrm{dL}$, in patients with insufficient vitamin D3 was $9.95 \pm$ $0.62 \mathrm{mg} / \mathrm{dL}$ and in patients with sufficient vitamin D3 was $10.16 \pm 1.09 \mathrm{mg} / \mathrm{dL}$. Serum calcium level was the highest in patients with adequate vitamin $\mathrm{D}$ levels and the lowest in patients with vitamin D deficiency, but this difference was not statistically significant.

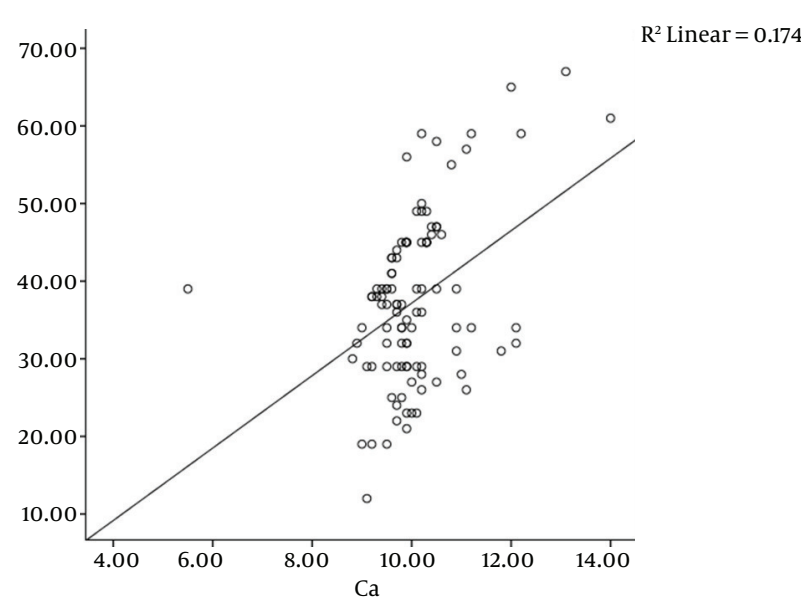

Figure 1. The Correlation Between Serum Levels of Calcium and Vitamin D3

The mean serum levels of vitamin D3 and calcium in patients with a positive family history of renal stones were $35.05 \pm 12.64$ and $9.89 \pm 1.4 \mathrm{ng} / \mathrm{mL}$ and in patients without a family history of renal stones were $38.05 \pm 18.37$ and 10.10 $\pm 0.83 \mathrm{ng} / \mathrm{mL}$, respectively. Serum levels of vitamin D and calcium level were not significantly associated with family history of renal stones ( $\mathrm{P}=0.27$ and $\mathrm{P}=0.38$, respectively).

The mean serum levels of vitamin D3 and calcium in patients with unilateral renal stones were $35.87 \pm 10.31$ and $10.03 \pm 1.18 \mathrm{ng} / \mathrm{mL}$ and in patients with bilateral stones were $41.31 \pm 11.39$ and $10.07 \pm 0.87 \mathrm{ng} / \mathrm{mL}$, respectively. Vitamin D levels were significantly higher in patients with bilateral renal stones $(P=0.03)$. Serum calcium level was not significantly associated with uni- or bilateral stones $(\mathrm{P}$ $=0.84)$.

Vitamin D levels in children $<4$ years were $36.4 \%$ and $63.6 \%$ insufficient and normal, respectively. Vitamin D levels in children 4 - 6 years were $31.7 \%$ and $63.8 \%$ insufficient and normal, respectively; vitamin D levels in children $>6$ years were $40 \%$ and $60 \%$ insufficient and normal, respectively. There was no significant difference between the groups $(\mathrm{P}=0.82)$. 


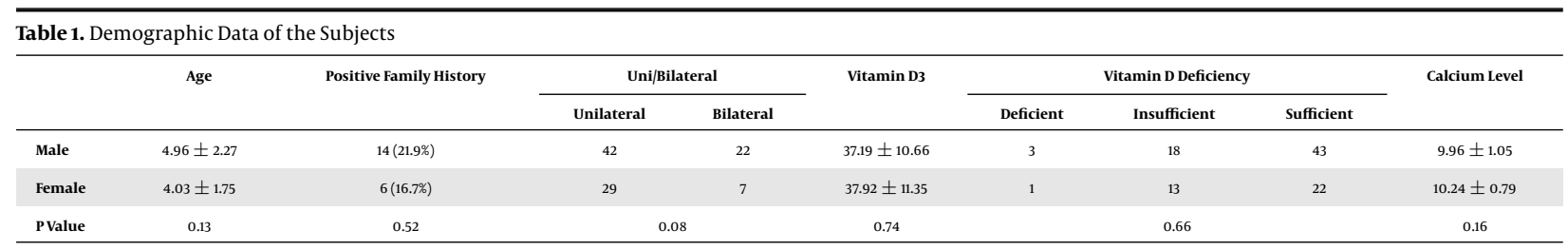

\section{Discussion}

The study found that urinary stones were more common in males and vitamin D levels were significantly higher in children with bilateral stones than patients with unilateral stones.

Fallahzadeh et al. (9) showed significant relationship between vitamin $\mathrm{D}$ and calcium levels. This finding confirmed the current study results. But the current study demonstrated that vitamin D level was lower in children with urinary stones. Perhaps due to the different age groups; Fallahzadeh et al. examined infants, while in the present study investigated children. Fallahzadeh did not compare the variables in males and females because of equal prevalence of urinary stones in male and female newborns. In the present study, due to higher prevalence of urinary stones in males, the impact of gender on all variables was examined.

Ramos et al.,(11) concluded that calcium plus vitamin D supplements did not increase urinary stones, but played a role as a protective factor in the development of stones. According to the current study, vitamin D supplements may reduce development of urinary stones.

Mohammadjafari et al., (12) showed the prevalence of $64 \%$ in male patients, which was higher than that of the present study, and positive family history.

Nguyen et al., (13) demonstrated no relationship between vitamin D levels and urinary stones. The current study concluded that vitamin D levels were significantly higher in children with bilateral stones than those with unilateral stones.

\subsection{Conclusion}

The current study concluded that serum levels of vitamin D in children with urinary stones were low and it was significantly associated with severity of the disease and the patients' serum calcium. Finally, it is recommended to evaluate metabolic disorders. It is also recommended to consider a number of healthy children as a control group and compare the results with those of a control group. Researchers can also evaluate the role of vitamin D supplements on the development of urinary stones.

\section{Footnote}

Authors' Contribution: All authors contributed equally in this project.

\section{References}

1. Davidson PJ, Sheerin IG, Frampton C. Renal stone disease in Christchurch, New Zealand. Part 2: a community study on the burden of renal stone disease. N Z Med J. 2009;122(1297):57-67. [PubMed: 19649002].

2. Bensalah K, Tuncel A, Gupta A, Raman JD, Pearle MS, Lotan Y. Determinants of quality of life for patients with kidney stones. $J$ Urol. 2008;179(6):2238-43. doi: 10.1016/j.juro.2008.01.116. [PubMed: 18423704].

3. Matlaga BR, Lingeman JE. Surgical management of stones: new technology. Adv Chronic Kidney Dis. 2009;16(1):60-4. doi: 10.1053/j.ackd.2008.10.008. [PubMed:19095207].

4. Bagrodia A, Gupta A, Raman JD, Bensalah K, Pearle MS, Lotan Y. Predictors of cost and clinical outcomes of percutaneous nephrostolithotomy. J Urol. 2009;182(2):586-90. doi: 10.1016/j.juro.2009.04.014. [PubMed: 19535106].

5. Nuss GR, Rackley JD, Assimos DG. Adjunctive therapy to promote stone passage. Rev Urol. 2005;7(2):67-74. [PubMed: 16985812].

6. Alaya A, Belgith M, Hammadi S, Nouri A, Najjar MF. Kidney stones in children and teenagers in the central coast region of Tunisia. Iran J Pediatr. 2012;22(3):290-6. [PubMed: 23400694].

7. Taylor EN, Stampfer MJ, Curhan GC. Dietary factors and the risk of incident kidney stones in men: new insights after 14 years of follow-up. J Am Soc Nephrol. 2004;15(12):3225-32. doi: 10.1097/01.ASN.0000146012.44570.20. [PubMed:15579526].

8. Shahverdi E, Konjedi MA, Shahverdi A, Dehghanian A, Khedmat H. Vitamin d and its role in ulcerative colitis. Thrita. 2015;4(4).

9. Fallahzadeh MH, Zare J, Al-Hashemi GH, Derakhshan A, Basiratnia M, Arasteh MM, et al. Elevated serum levels of Vitamin D in infants with urolithiasis. Iran J Kidney Dis. 2012;6(3):186-91. [PubMed: 22555482].

10. Rabbani A, Alavian SM, Motlagh ME, Ashtiani MT, Ardalan G, Salavati $A$, et al. Vitamin D insufficiency among children and adolescents living in Tehran, Iran. J Trop Pediatr. 2009;55(3):189-91. doi: 10.1093/tropej/fmn078. [PubMed: 18775944].

11. Ramos M, Santana L, Rasvickas CV, Teixeira V, Schor N. Effect of vitamin d3overdose and calcium supplementation in experimental nephrolithiasis model. J Bras Nefrol. 2014;36(2):132-8. doi: 10.5935/0101-2800.20140022.

12. Mohammadjafari H, Barzin M, Salehifar E, Khademi Kord M, Aalaee A, Mohammadjafari R. Etiologic and epidemiologic pattern of urolithiasis in north iran;review of 10-year findings. Iran J Pediatr. 2014;24(1):69-74. [PubMed: 25793048].

13. Nguyen S, Baggerly L, French C, Heaney RP, Gorham ED, Garland CF. 25-Hydroxyvitamin D in the range of 20 to $100 \mathrm{ng} / \mathrm{mL}$ and incidence of kidney stones. Am J Public Health. 2014;104(9):1783-7. doi: 10.2105/AJPH.2013.301368. [PubMed: 24134366]. 